\title{
25 Research Square \\ Quality-of-life Profile Of The Elderly Residing In A Very Low Population Density Rural Area
}

\section{Maria Goes}

Instituto Politecnico de Beja Departamento de Saude

\section{Manuel Lopes}

Universidade de Evora Escola Superior de Enfermagem Sao Joao de Deus

Henrique Oliveira ( $\nabla$ hjmo@lx.it.pt)

Instituto de Telecomunicacoes https://orcid.org/0000-0001-8687-4291

\section{César Fonseca}

Universidade de Evora Escola Superior de Enfermagem Sao Joao de Deus

Marôco João

Instituto Universitario de Ciencias Psicologicas Sociais e da Vida

\section{Research article}

Keywords: Aging. Quality of life. WHOQOL-BREF. Nursing

Posted Date: October 29th, 2019

DOI: https://doi.org/10.21203/rs.2.16529/v1

License: (ㅇ) (i) This work is licensed under a Creative Commons Attribution 4.0 International License. Read Full License 


\section{Abstract}

This paper describes the Quality-of-Life profile of the elderly residing in an inland region located at middle south of the Portugal main territory, presenting a larger area and low population density, which is composed of several items, extracted after statistics analysis of the data taken from the European Portuguese version of WHOQOLBREF. Cross-sectional, descriptive study, with a random sample composed of elderly individuals residing in the community. Data collected by health professionals in the participants' houses, using the European Portuguese WHOQOL-BREF instrument. The factorial validity was assessed by a confirmatory factor analysis. Appropriate statistical tests were used for comparison between mean Quality-of-Life scores according to gender, age group, marital status and educational level. Regression models were used to identify the biological and sociodemographic possible predictive factors of Quality-of-Life and the possible predictive domains of the General-Health-Facet. All Quality-of-Life domains and the General-Health-Facet decreased with advancing age. A higher and lower mean scores were observed, respectively for the Social Relationships and Physical Health domains. Males had higher mean Quality-of-Life scores than females, while widows and older women had the lowest ones when compared to other individuals. Educational level was the most significant sociodemographic predictive factor of Quality-of-Life domains, with scores increasing as the educational level increased. Moreover, Physical Health domain was the strongest predictor of the General-Health-Facet. The authors think that all the information extracted from the proposed Quality-of-Life profile, constitutes an important empirical basis that allow for more a detailed outcome of a concrete health care needs of the elderlies, leading to a concise planning and monitoring of health interventions and health policies management, extending the current general knowledge on Quality-of-Life. With this Quality-of-Life profile, which was never been made for the elderly population residing in Region of Baixo Alentejo, the authors expect "to find out what is really important for the elderlies, based on the rule: "better to know for better care".

\section{Background}

Estimates carried out by several national and international organizations [e.g., Statistics Portugal (Instituto Nacional de Estatística - INE), the European Commission (EC), the World Health Organization (WHO), and the United Nations (UN)] have shown an increase in population aging, which invariably influences the development of society and health care planning (1).

At the population level, Portugal has one of the highest resident population aging indexes among the European Union countries (148.7 elderly per 100 young) (2), and national estimates indicate that this rate will more than double by 2080 [(317 elderly per 100 young) (3)]. The National Health System (Serviço Nacional de Saúde SNS) in Portugal's main territory is divided into five Regional Health Administrations (4). One of these is the Regional Health Administration of Alentejo, which is subdivided into four sub-regions, including the Local Health Unit of Baixo Alentejo [Unidade Local de Saúde do Baixo Alentejo - ULSBA (5)], whose geographical boundaries is called the Region of Baixo Alentejo - RBA; see Fig. 1a and b for details (Baixo Alentejo is the name designated by the Portuguese Municipalities Council and the Local Health Unit of Baixo Alentejo is the name designated for the same region by the National Health System). The RBA (or ULSBA) covers an area of $8.544 .6 \mathrm{~km}^{2}$ (corresponding to $10.8 \%$ of the main territory) and is an inland region located in the middle-south of the country that borders Spain with the Region of Estremadura. It was chosen for this study because it is undergoing a delicate, worrying, and heterogeneous socio-demographic trend of population aging (6): (i) rural 
areas prevail to a larger extend, with traveling distances between villages ranging from $20 \mathrm{~km}$ to more than $100 \mathrm{~km}$; (ii) it has only one Hospital belonging to the National Health System and is located in Beja (the capital of RBA). Regarding the emergency service (ES), for a citizen residing in Barrancos (a village located on the east side of RBA) who presents an acute health care situation and needs to receive $E S$, he/she must undertake almost 1.5 hours of travel time, covering a distance of approximately $102 \mathrm{~km}$ in an emergency vehicle (data provided by Google Earth); (iii) the public transportation network in RBA is scarce and inefficient, thus causing mobility inequalities whiting the territory, including some cases where people is unable to travel by their own means (e.g. using they own car); (iv) the RBA has the lowest population density of the country [14.8 individuals per $\left.\mathrm{Km}^{2}\right)(7)$ ] because it has almost the lowest resident population combined with the largest geographic area in relation to all regions of the country; $(v)$ it is identified as an aged region, presenting an important aging index of 189.2 elderly per 100 young (8); and (vi) the Regional Health Administration of Alentejo (i.e. the RBA), presented the highest standardized mortality rate in the country for citizens greater than 65 years of age due to intentional self-harm (suicide), ranging from 40 to 60 citizens per 100,000 inhabitants, between 2010 and 2016, and the $2^{\text {nd }}$ highest in 2017 (9). The main reasons for this have been identified as being related to (i) aging, (ii) high illiteracy levels, (iii) low self-esteem, (iv) a fragile economic situation among families (low incomes in terms of paid pensions, since most of the rural population is retired), (vi) few job opportunities, and (vii) low levels of home care support to the most isolated residents. These factors are as such because areas with geographically dispersed residents have a very low population density, leading to isolation and loneliness in rural areas (10).

Another topic concerning health resources in the RBA is related to the National Network of Integrated Continuing Care (RNCCl - Rede Nacional de Cuidados Continuados Integrados), a structure (among others) of the National Health System. The RNCCI maintains a set of Integrated Continuing Care Teams (Equipas de Cuidados Continuados Integrados - ECCl), which are multidisciplinary home care teams, under the supervision of primary health care and social support entities. These teams provide services at home to citizens who have functional dependency, terminal illness or are convalescent and whose situation does not require hospitalization, but they cannot be relocated. Since each ECCI is allocated to each municipality, and the RBA includes only 6 ECCls (11) and 13 municipalities (12), it is the region of the country presenting the lowest ECCl coverture rate, at only $46.2 \%$ (see Fig. 1c for details). Regarding deaths by certain causes, the Regional Health Administration of Alentejo presented the major percentages of the country between 2011 and 2017, for example, in relation to diabetes, diseases of the circulatory system and, in some years, diseases of respiratory system (13).

On the individual level, human aging is a complex phenomenon due to several physical, psychological, social and, environmental changes that directly affect a person's quality-of-life (QOL). As people age, they become increasingly fragile, they present functional impairments and multimorbidity, and there is a significant prevalence of chronic conditions that decompensate easily; the elderly frequently receive health care in a fragmented, reactive, and episodic way at the emergency services (ES). The elderly use ES more often than any other age group, and ES crowding is a widespread and growing problem due to the increased elderly population (14). These health units are not adequately prepared to deal with the specific health care needs of elderly people due to the multimorbidity scenario that they present, and the ES only tries to address their acute problems. According to an assessment of the Portuguese health system (15), the distribution of the burden of chronic diseases is estimated as follows: (i) $18 \%$ of the Portuguese health system users have one chronic disease; (ii) 
$11 \%$ have 2; (iii) $8 \%$ have 3; and (iv) $22 \%$ have 4 or more. Therefore, it is estimated that approximately $59 \%$ of users present one or more chronic disease.

It is known that health/disease processes associated with aging are fundamentally associated with the management of chronic, multiple, and complex diseases (16) and that the aim of health-related interventions is not to cure but rather to reduce the impact of these diseases on the various dimensions of a person's life. Therefore, it is important to understand the concerns, hopes, and expectations of elderly people and not simply address their deficiencies and disabilities based on a simplistic biological and functional perspective (17). Thus, the assessment of QOL will enhance the decisions made by health professionals aimed at multi- and interdisciplinary actions, as this model considers the person and all of the components that promote or hinder the execution of his/her activities, as health is "a state of complete physical, mental and social well-being and not merely the absence of disease", a concept adopted by the WHO in 1946 (17). As stated by (18), evaluating QOL will capture the dynamic interaction between the external conditions of an individual's life and the internal perception of those conditions.

The strong worldwide interest in the QOL concept, combined with the heterogeneity of its definition, led the WHO, through the WHOQOL group, to develop the most comprehensive concept for this found in the scientific literature (19). Because of the work undertaken by the WHOQOL group, the WHOQOL-BREF was developed for QOL assessment (a shortened version of the WHOQOL-100 instrument that preserves their 24 facets; this was translated/validated in several countries, including to Portugal (a country in southwest Europe), by the WHOQOL Portuguese team (20). Some of their work is published in (21), which was used in our paper, and it is crosscultural and can be applied to individuals living in different contexts. Additionally, WHOQOL-BREF is generic (it includes Physical Health, Psychological, Social Relationships, and Environment domains and also a General Health Facet - GHF), thus allowing the evaluation of a wide range of aspects of people's lives (including those aged 65 years or older), even when different health conditions are present (22). It was also the most widely used instrument in $91.7 \%$ of 48 scientific studies included in a bibliometric analysis of QOL assessment and, thus, the instrument with the best applicability according to the literature review work developed by (23).

Studies of QOL in rural areas have been increasing in recent years, leading to an increase of scientific publications related to this topic. In general, rural areas reveal a higher level of aged population when compared to urban areas, along with a geographic distribution that is characterized by a large dispersion of small or very small population groups over large areas. According to several published studies, these two main characteristics of rural areas have given rise to the problems of isolation and loneliness among the elderly population, as suggested by (24), (25), (26), (27), (28). Moreover, greater isolation and loneliness associated with alcohol abuse, higher suicide rates, and high rates of poverty and depression were the main research findings in the rural areas of 15 countries (mainly European) by (29), with some of these results also found by (30). These authors suggest that the problem may be reduced through the implementation of social interaction activities based on the creation of recreational facilities and the promotion of literacy. In Portugal, there is also scientific evidence in relation to isolation and loneliness of the rural elderly population, as revealed by (31), where one third of the Portuguese elderly population is afflicted with social isolation, being more prevalent in women who live alone. Other studies involving the Portuguese older population reinforce the problems of isolation and loneliness in the rural context due to the increased migration of young and active people from 
rural to urban areas, leading to the loss of potential family caregivers, as well as the lack of social and health services (32), (33) e (34).

Two studies carried out in India and involving elderly people living in rural areas (26) and (35), showed similar findings in relation to the above studies, where the number of women was greater than the number of men, with people presenting comorbidities, although most of referred to having a very good ("best") QOL. The Physical domain reached the highest QOL score, with the Social Relationships domain presenting a similar score, and the Psychological domain presenting the lowest score. Finally, the authors identified the following as statistically significant determinants of a good QOL, not having chronic diseases, having a good financial income, not living alone, having an occupation (e.g., a job), and being younger than 70 years old. In Brazil, in a rural area of the state of Minas Gerais, whose population sample showed a similar number of men and women and who were mostly married, with low education levels and low incomes, the authors emphasized that these elderly people were mostly satisfied with their lives, although some of them suffered from diseases and impairments (27). According to (29), the authors concluded that the lowest QOL scores were observed in the Mediterranean cluster of countries (Spain, Italy and Israel), and the lower QOL scores were associated with physical and mental health as people aged. Additionally, literacy problems were found, affecting more people residing in rural areas than in urban areas. In a Portuguese study (36), the authors concluded that thenumber of the oldest women is greater than the number of the oldest men, where more than a half were widowed and almost half were illiterate. As people aged, they showed significant difficulties in performing activities of daily living. According to (31), the oldest women have the lowest levels of literacy, with a negative impact on QOL, leading the authors to recommend the involvement and integration of the elderly in social networks and the promotion of relations and educational actions. According to an assessment of the Portuguese health system (15), actions to improve healthy life expectancy, especially among older women, may also be emphasized.

Researching the relationship between biological and sociodemographic factors with QOL has been more frequent in populations presenting a specific health context (37), (38), (39). According to (40), studding the relationships between the biological and sociodemographic factors of QOL will lead to a more rigorous evaluation of the effects of interventions carried out in specific populations. The scientific literature on this subject has increased in recent decades, and there are recent published research that enhance the importance of studying the relation between those and other factors regarding QOL; the authors state that studying those factors and their relation with QOL can provide public health indications that could support concrete actions (41), (42), (43), (29). Thus, the authors of the current study found their motivation based on the above, i.e., studying the relationship between biological (age and gender) and sociodemographic (marital status and education level) factors with QOL in the RBA population reveals important features, as mentioned in the second paragraph of this introduction. This study is expected to clarify more detailed outcomes that could lead to more concrete actions regarding health care needs and health policies management to be applied to this type of population based on the rule "better to know for better care". In particular, this type of study was never before carried out for the elderly population residing in RBA.

Thus, the goal of the present study was to delineate the QOL profile of the elderly residing in a rural context of very low population density. The following objectives were established: (i) biological and sociodemographic characterization (descriptive statistics); (ii) analysis of the factor score weight (fsw) based on confirmatory factor analysis (CFA) and the mean scores obtained for each of the 24 facets; (iii) calculation of the average 
score of each QOL domain and also stratified according to the biological and sociodemographic factors; (iv) how age varies with QOL domains and GHF scores by gender; (v) inference regarding which biological and sociodemographic factors should be considered as possible predictors in each QOL domain; and (vi) QOL domains that should be considered as possible predictors of GHF. We also segmented the sample data based on the question "Are you currently ill?" The authors of this study believe that this research is scientifically relevant since it constitutes an important empirical basis for a concrete level of health care needs of the elderly who reside in rural areas with a low population density, leading to a concise planning and monitoring of health interventions, thus extending the current general knowledge on QOL, as stated in (36).

Finally, although the WHOQOL-BREF psychometric properties have been studied for the Portuguese population, none of the studies included specifically the elderly population residing in an area with very low population density. Since aging and the QOL of older people are a concern, we reevaluate the psychometric properties of the WHOQOL-BREF for the elderly population using CFA, and both type of population and analysis methods are reported here for the first time; they were not reported on by the Portuguese WHOQOL group during the respective WHOQOL-BREF validation work published in (22). Moreover, the analysis of $f s w$ values, extracted from the CFA model, can help to select the most important facets of the WHOQOL-BREF (presenting high values of $f S w$ ), as well as those with respective lower importance (presenting lower values of $f s w$ ), because they represent facets that contribute differently to the QOL profile. These $f s w$ can also be used as weights to compute the scores of QOL domains and GHF.

\section{Methods}

\subsection{Subjects}

This study involved persons aged 65 years or older who were registered in the National Health System at RBA, namely, in ULSBA (5)]. The sample size was calculated adopting the formulae proposed by (44) and (45), stratified by gender (male and female) and age group ( 65 to 74,75 to 84 , and 85 or more years) using the Neyman optimal allocation based on the total of elderly people listed in the ULSBA database (32893). The calculated sample size was 468 people who were randomly selected from the entire ULSBA elderly database. The inclusion criteria adopted were, cumulatively: (i) individuals aged 65 or older; (ii) those interested in participating in the study; (iii) individuals residing in the RBA (composed of 13 municipalities) in their own home or at a family or friend's home; and (iv) those who were able to make decisions, even if sick or hospitalized. The final sample totaled 351 elderly individuals who signed the informed consent form, filled out the Portuguese WHOQOL-BREF questionnaire, and fulfilled the inclusion criteria.

Data were collected between January 2016 and April 2017 at the individuals' homes by teams of health professionals from ULSBA using the Portuguese WHOQOL-BREF after prior authorization by the authors of the Portuguese WHOQOL-BREF version, whose details regarding the translation-back translation procedure of the QOL measure were published in (21). The data acquisition for the Portuguese WHOQOL-OLD instrument adaptation and validation tasks started at the end of March 2016, i.e., 3 months after we started our data acquisition, and according to the respective authors (46), it is not a finished work, because as stated in their publication "... future studies will be conducted to increase the validity of the instrument: confirmatory factorial analysis and the influence of sociodemographic variables analysis, including effect size and the normative study...". Prior to each interview the health professional presented the informed consent form to the individual 
and the family; the informed consent was specially developed for this study and was previously approved by the ethics committee of ULSBA. The informed consent was fully read by the individual in the presence of the health professional (in cases where they were able to read it) or it was read aloud by the health professional in cases where the individual did not know to read. Information about the objectives of the study was given to the individuals and their families, stating that confidentiality and anonymity would be guaranteed. The interviews lasted at least 30 to 45 minutes depending on the individual's age and their level of literacy, and the interview started only after they had agreed to participate in the study and had freely signed the informed consent form. At any time the study participants could cancel the interview if they wanted to.

\subsection{Statistical procedures}

The used flow diagram of analyses is shown in Fig. 2 and described as follows. The six yellow boxes identify the output contents that compose the proposed QOL profile, as follows: (i) biological and sociodemographic characterization of the sample, (ii) fsw and mean scores of facets, (iii) domain scores (globally and also stratified by the biological and sociodemographic factors), (iv) how age varies with QOL domain and GHF score by gender; ( $v$ ) biological and sociodemographic factors that are possible predictors in each QOL domain, and (vi) QOL domains as possible predictors of GHF. Another output not belonging to the QOL profile was proposed, namely, "Are you currently ill?"; this was used here to assess the perspective of the participants in relation to how they feel regarding their current health state and constitutes a possible predictor of the general QOL status. Having one or several diseases, which is something most people in the sample will inevitably have, is different from feeling ill. The answer to that question refers to whether there is a significant difference in one's health state compared to their normal health state.

All the statistical calculations were performed with IBM SPSS Statistics for Windows, Version 23.0 (IBM, Armonk, NY). At the beginning of next section of this paper, descriptive statistics are presented to characterize the variables of the participants (biological and sociodemographic factors) corresponding to the procedures block "Statistical descriptive analysis" and the respective results block, constituting the first element of QOL profile.

The Portuguese WHOQOL-BREF factorial validity was evaluated by confirmatory factor analysis (CFA) using IBM SPSS AMOS version 23.0.0 (IBM, Armonk, NY) following the procedures described in Marôco (47), notably: (i) Construct reliability, which was assessed using Cronbach's alpha (a) and an alternative measure known as composite reliability (CR), both calculated for each of the four QOL domains; (ii) Construct validity, which was evaluated via analysis of the factor loadings (factorial validity); and (iii) the average variance extracted (AVE) for each domain (convergent validity). Because the maximum-likelihood was used to estimate the model parameters in CFA, the normality assumption was tested by analyzing the skewness and kurtosis. The quality of the overall model fit was based by several indices, as suggested by Marôco (47). The fsw were used to identify the most valued facets in each QOL domain. All of these procedures are identified in flow diagram of analysis by a procedure block "confirmatory factor analysis" and a respective results block, which constitutes the second element of the QOL profile.

Student's t-test (see respective procedure block in Fig. 2) was used to assess differences between the mean scores obtained in the different QOL domains and in the GHF in relation to gender after verifying that the distributions were not strongly asymmetric; the highest absolute skewness and kurtosis values were 0.577 and 
0.874 respectively. The homogeneity of variances of the scores for both genders were also assessed. To investigate the same type of differences among age groups, educational levels, and marital status, the nonparametric Kruskal-Wallis $\mathrm{H}$ test was used, with subsequent multiple comparison of pairs of means rank using a posteriori (post hoc) multiple comparison tests. This corresponds to the results block represented in Fig. 2, below the previously mentioned procedure block, constituting the third element of QOL profile.

To study the association of the QOL score with age, Spearman's rank-order correlation $\left(R_{s}\right)$ was used, has represented in Fig. 2 by the corresponding procedure block and linked to the receptive results block, identified as the fourth element in the QOL profile.

Two regression models were calculated: (i) a blocks linear regression model (see correspondent procedure block) for each QOL domain was used to identify the sociodemographic variables that were possible predictive of the QOL (a first block incorporating the biological variables-gender and age and a second block incorporating the sociodemographic variables-educational level and marital status) (48); these results are identified by the results block linked to the previous procedure block, which constitutes the fifth element of the QOL profile; and (ii) a multiple linear regression (MLR) model (see respective procedure block in Fig. 2) was used to check the Physical Health, Psychological, Social Relationships and Environment domains as possible predictors of the GHF (22); the respective results block constitutes the last (sixth) element of the QOL profile.

The answer to the question "Are you currently ill?" on the Portuguese WHOQOL-BREF was analyzed using the non-parametric Mann-Whitney $U$ test to assess whether there were significant differences in the mean QOL scores between those who answered "Yes" and those who answered "No". The 5\% significance levels were adopted in all statistical analyses.

Finally, here we summarize the research questions proposed in this paper considering the attributes of the RBA that are distinct from other regions of the country (see yellow blocks in Fig. 2): (i) What are the main biological and sociodemographic characteristics of the elderly population? (ii) What are the most valued facets (based on fsw) and their average scores? (iii) What are the average QOL domain scores, globally and stratified by biological and sociodemographic factors? (iv) How does age vary with QOL domain and the GHF of the elderly population? ( $v$ ) What biological and sociodemographic factors are possible predictors of each QOL domain? (vi) What QOL domains are considered as possible predictors of GHF? We also investigated whether the question "Are you currently ill?" can be used (or not) to differentiate individuals based on their perspective of how they feel in relation to their QOL ("better" or "worse"); i.e., if a person responds "Yes", it is possible that he/she feels that their QOL is "good" (better), or in the opposite case, when he/she answers "No", they likely feel their QOL to be "worse" (see Fig. 2, left side).

\section{Results}

\subsection{Biological and sociodemographic characterization}

Regarding the study sample, the minimum age of the respondents was 65 (expectable) and the oldest person was a 101-years-old female (mean $=78.08, S D=7.86$, median $=78$; a higher proportion of females than males was observed (see Table 1). Regarding marital status, the six categories present in the Portuguese WHOQOLBREF were reduced to three because the absolute frequencies in some categories were minimal (less than or 
equal to 5 in the categories "Living as Married", "Divorced" and "Separated"). The majority of respondents were married, and a considerable proportion was widowed $(32.5 \%$, of whom $76.3 \%$ were women and $23.7 \%$ were men). Regarding education, the eight categories listed in the Portuguese WHOQOL-BREF were reduced to four, again because the absolute frequencies in some categories were minimal. Approximately half of the respondents $(46.4 \%=29.6 \%+16.8 \%)$ had no education, and $29.6 \%$ were illiterate (of whom $57.8 \%$ were women and $42.2 \%$ were men).

\subsection{Confirmatory factor analysis, fsw, and mean scores of 24 facets}

The initial CFA model showed poor overall quality of fit (see Table 2). The 24 facets showed no severe violation of normality, as the maximum absolute values obtained for both skewness and kurtosis were less than 1.3. For a better model fit, the measurement errors between some facets were correlated (see Fig. 3). These correlations, as suggested by the modification indices (MI), led to a better overall model quality of fit, from "poor" to "good" [textual classification according to Table 4.1 in Marôco (47)], since the value of MECVI=2.061 was lowered (see Table 2 and Fig. 3).

Table 3 lists the results of composite reliability. The values of the 24 standardized factor loadings were all higher than 0.3 (the threshold considered appropriate for this type of construct), with $20.8 \%$ presenting values between 0.3 and 0.5 (two in the Physical Health domain and four in the Environment domain) and the remaining $79.2 \%$ always being higher than 0.5 . These results suggested that the factorial validity of the construct was "favorable". The results regarding convergent validity are also listed in Table 3.

Table 4 lists the estimated $f s w$ values of facets when they are greater than 0.05 (empirically chosen) in the CFA model. Regarding the Physical Health domain, facets 10 and 12 presented the highest $f s w$ values (they were also the highest when all 24 facets were analyzed), which were greater than three times higher than those obtained for facets 2 and 9. For the Psychological domain, facet 6 is highlighted, with the remaining facets presenting $f s w$ values approximately 2.5 times lower. In the Social Relationships domain, facet 13 was the most valued, and facet 15 had the lowest $f s w$, with the latter also presenting a mean score $(M=2.92)$ lower than 3 (the third lowest among all 24 facets). Finally, facet 20 was found to be the most valued in the Environment domain, with the remaining 3 presenting similar $f s w$ values. Facet 21 presented the lowest mean score $(M=2.74)$ among the 24 included in the CFA model, and facet 18, "Economic resources", had the second lowest mean score $(M=2.87, f s w=0.022)$, although facet 17 had the highest mean score among all 24 facets $(M=3.83)$.

\subsection{Average score of each QOL domain, also stratified according to biological and sociodemographic factors}

With respect to the four QOL domains, the results listed in Table 5 indicate that the highest and lowest scores were obtained for the Social Relationships and Physical Health domains, respectively. An even lower score was observed for the GHF than for the Physical Health domain.

Regarding biological and sociodemographic variables, Table 6 shows that mean QOL scores significantly differed between men and women for the Physical Health $(p<0.001)$ and Psychological $(p=0.003)$ domains, tending to be greater for men than for women. Regarding the three age groups (see Table 6), the differences among the mean rank scores in all QOL domains were always highly significant when comparing the younger group (65 to 74 years of age) with the other two groups (multiple comparisons: 65 to 74 years differed from 75 to 84 years and 85 and older, $p<0.01)$. Regarding marital status, based on multiple comparisons, at least one 
group (married/living as married) had a mean QOL score different than that of the other groups in all four domains, with a significant difference relative to the widowed group $(p<0.05)$. Moreover, only in the Psychological domain was there a highly significant difference in QOL scores between the married/living as married respondents and the single/divorced/separated respondents $(p<0.01)$. An analysis of QOL variability as a function of educational level indicated that in at least one group, the mean score differed from that of the other groups in all domains and in the GHF ( $p<0.05$ for all comparisons); in addition, a potential increasing trend in the mean scores of the QOL domains as educational level increased was observed, although differences among all groups were not always statistically significant. Multiple comparisons revealed that in all QOL domains, mean scores were always significantly different for respondents with more education relative to those who did not know how to read or write (does not know how to read or write differed from $1^{\text {st }}-4^{\text {th }}$ grade and more education, $p<0.05$ ) and in the GHF (does not know how to read or write differed from more education, $p<0.01)$.

\subsection{How age varies with $Q O L$ domain and GHF score by gender}

Regarding the correlations between age stratified by gender and QOL score (see Table 7), the results indicated that they were statistically significant, except for the GHF of female respondents. The $R_{s}$ values were always negative, suggesting that as age increases, the QOL decreases (simultaneously for men and women), but this outcome was always more pronounced in men than in women.

\subsection{Biological and sociodemographic factors considered as possible predictors in each QOL domain}

The possible predictive biological and sociodemographic factors in the various domains of the Portuguese WHOQOL-BREF, identified through multiple block linear regression models (48), are shown in Table 8. Age was a significant possible predictor in the Physical Health and Environment domains, while Gender was a significant possible predictor in the Physical Health and Psychological domains. Education was a significant possible predictor in all four domains, while marital status was significant in the Psychological and Social Relationships domains. The variances explained by the models ranged from 17.1\% (Psychological domain) to 10.4\% (Social Relationships domain). In all linear models, the respective total variance explained was always higher after adding the second block, with the following positive increases: (i) $5.3 \%$ for the Physical Health domain; (ii) $14.7 \%$ for the Psychological domain; and (iii) $6.9 \%$ for the Environment domain.

\subsection{QOL domains considered as possible predictors of GHF}

The four QOL domains were subsequently input into a MLR model (using the Forward stepwise method) as explanatory variables, with the GHF as a dependent variable, aiming to achieve a parsimonious model that enables predicting the score of the GHF as a function of the four domains scores. The initial model $(F=157,344$, $p<0.001$ ) explained $57.6 \%$ of the variability in the response variable and the Social Relationships domain was not identified as statistically significant (standardized coefficient, $p=0.480$ ), with the increase in the total explained variance due to its input in the model being $0 \%$. The model was recalculated with only the three remaining domains considered as significant possible predictors of the GHF, showing 19 (5.4\%) observations that presented studentized residuals (in absolute value) with a probability of type I error less than $5 \%$, these were considered as outliers. The final model $(F=215,213, p<0.001)$ now explained $66.3 \%$ of the total GHF variability. Both the Physical Health and Psychological domains had the highest, although similar, levels of

Page 10/30 
importance (standardized coefficients, $p<0.001$ and , $p<0.001$ ) to explain the behavior of GHF, which was approximately twice that of the Environment domain (standardized coefficient , $p<0.001$ ). The variance shared by the three domains reached $80.9 \%$ of the total explained variance, with all variance inflation factors being less than 2.430 .

\section{7. "Are you currently ill?"}

The response to the question "Are you currently ill?" suggested that people who responded "No" presented a significantly higher mean QOL score in all four domains and the GHF compared with those who answered "Yes"; the lowest $U$ value found was 17176.0 for the Social Relationships domain, $p<0.001$. These results suggest that this question may be used to distinguish (segment) those who claim to be ill and therefore exhibit worse QOL from those who claim to be healthy and exhibit better QOL. According to the observed data and using the nomenclature of the international classification of diseases (ICD), the diseases that most affect the respondents were, in descending order of proportion, diseases of the musculoskeletal system; diseases of the circulatory system; endocrine, nutritional and metabolic diseases; cancers; and diseases of the nervous system.

\section{Discussion}

The factorial validity of the Portuguese WHOQOL-BREF was tested using a CFA model, showing a good adjusted model. Strong correlations were observed among the instrument's four domains. The Social Relationships domain showed the lowest values for composite reliability and Cronbach's alpha $(a=0.604$ and $\mathrm{CR}=0.590$ ). Some authors have justified this reliability by the small number of questions included in this domain (22) and (49). Canavarro et al. obtained a value of only 0.64 . Moreover, the same was found during the validation work of the Brazilian-Portuguese WHOQOL-BREF coordinated by Marcelo Pio Fleck in Brazil, with "Social Relationships" being the domain presenting a Cronbach's alpha of less than 0.7 ( 0.69 respectively); this outcome was justified as previously mentioned. Some authors have stated that the minimum number of items for this type of analysis should be four items (49). Therefore, we believe that the Cronbach's alpha measured in "Social Relationships" constitutes a problem that has been previously noted regarding this construct and is not a specific problem found only in our research. Despite the abovementioned issue, the Cronbach's alpha does not only depend on the number of test items ( $\mathrm{N}=3$ in our case) but also on the average inter-item covariance among the items (we had low values in our case regarding "Social Relationships": ) and the average variance of the items (we found a high value regarding this variable: ) (50). These three issues all contribute to the lower value achieved for this index $(a=0.604)$. To obtain a Cronbach's alpha greater than or equal to 0.7 for 3 items in a factor, respective general solutions can be found on Graph 1, varying and in a certain value range. Our Cronbach's alpha is represented in Graph 1 by a plus signal, although it is outside of the yellow area, i.e., that corresponding to a Cronbach's alpha greater than or equal to 0.7 . Therefore, to obtain a good solution in our case, the average inter-item covariance among the items should be much higher than 0.192 , and the variance should simultaneously be much lower than 0.570 .

In relation to the GFI value of 0.871 , CFA simulations using only 3 factors indicated that the best GFIs were obtained when the "Environment" QOL domain was removed, after adjustments based on the item error correlations suggested by the Ml>11: (i) ; (ii) $\mathrm{CFI}=0.950$; (iii) PCFI=0.784; (iv) GFI=0.920; (v) PGFI=0.670; (vi) TLI=0.940; (vii) SRMR=0.0504; (viii) RMSEA=0.066; (ix) $\mathrm{Cl}_{90 \%}$ ]0.056-0.076[; (x) $p<0.005$. However, a lower quality of model fit was expected when using the four factors, because this domain presents the lowest factor 
loadings among all latent factors, as can be seen in Fig. 2 (three are lower than 0.5), and the average of all standardized regression weights related to "Environment" was also the lowest among the entire CFA model $\left(I_{\text {Average }}=0.540\right)$.

Taking into account the initial results, it was found that age groups over 75 years represented $62.4 \%$ of the elderly population of our sample. Based on an epidemiological study of functionality carried out by Lopes et al. (51) elderly persons aged 75 to 84 years present some degree of disabilities that requires care. In addition, therapeutic aid becomes necessary due to the progressive decline that can be seen after that age, with increasing percentages of functional impairments (51).

Our study followed the trend reported in some previous studies regarding the predominance of women (25), (52), (53), particularly in the oldest age group, a phenomenon known as the "feminization of aging" (54). The greater longevity of women appears to be related to biological and social aspects, as well as to a genetic advantage and a greater capacity for socialization, with more intense relational interactions between family and friends, providing better conditions for adaptability to aging, as detailed in (55). However, while women live longer than men, during those extra years they live with more dependencies (56), (57), (58), (59). Also noteworthy is the higher number of individuals with illiteracy, which is particularly prevalent in women. Regarding education level, our data showed that $29.6 \%$ of the participants stated that they could neither read nor write; a very similar result was found in (51). In our study, this population was predominantly female $(57.8 \%)$ and in the age groups of $75-84$ and 85 years and over.

Regarding disabilities and illiteracy, the latter is of great significance, as it represents a very important health determinant, and it greatly helps to explain the QOL findings. Moreover, illiteracy has an important historical reference within the rural context of Alentejo. Traditionally, women could not engage in paid work since they had to exclusively care for their family full time. Thus, due to the stress and time required as a caregiver, now that these women are older their economic situation is often more precarious than that of men who were able to engage in paid work. Being a caregiver to their children and then to their parents and husbands led women to reduce their engagement in the labor market (60).

The majority of the respondents were "Married/Living as Married", and almost half never went to school, with these two characteristics being frequently found on numerous scientific studies, particularly the low education levels. In Portugal, work in agricultural fields to precedence in relation to going to school, and educational institutions were generally located far from the agricultural areas. Transportation was also difficult due to the scarce and inefficient rural road networks. In general, the older Portuguese population attended school for a mean of 5.79 years (36).

Based on the fsw values (see Table 4), "10.Activities of daily living", "12.Work capacity", "6.Self-esteem", and "20. Opportunities for acquiring new information and skills" were identified as the most valued facets in the various domains to which they belonged when estimating the model scores.

Regarding the results of the confirmatory analysis, we found some interesting characteristics of our sample. For example, we highlight the importance of both "10.Activities of Daily Living" and "12. Work capacity". Taking into account the characteristics of the sample (mostly over 75 years of age) and the fact that this group has the highest levels of dependence, one of the main concerns about aging has to do with the loss of independence

Page $12 / 30$ 
(61), (62), (63), (64). Therefore, we are not surprised by the important role of facets 10 and 12 . The facet "20.0pportunities to acquire new information and skills" (high $f s w$ value) in the "Environment" domain was found to be very important. These results are even more compelling when related to the relevance given to "10.Activities of Daily Living" and "12.Ability to Work", because this shows that older people want to continue learning, which, is in fact, very surprising. On the other hand, the importance of " 12 .Work capacity" was surprising, which can be highlighted and combined with "10.Activities of daily living". Although this study pertains to a group of mostly retired people, in this case these concepts may not have the same meaning as they would in urban areas. Perhaps the attachment (commitment) to the land and the low pensions paid by the state to retired rural people (also evidenced in this research) may lead the elderly to maintain their "10.Activities of daily living". This also highlights the greater importance that dependency (inability to work) assumes in our QOL model. We cannot ignore the high suicide rate among the elderly in Alentejo, as well as the very common expression among them of "I'm no longer useful for anyone or to myself", with these two cases probably being related (or not) with the inability to work or with being unable to execute daily living activities (10).

These results seem to suggest that actions that would increase the scores of the mentioned facets, particularly those that reduce disabilities (physical or mental) and promote independency of the elderlies and that augment a person's ability to adjust to and control their lives, may have a greater impact on the perceived QOL; this theory is aligned with the findings in (65). However, it is also important to highlight the facets for which the worst mean scores were obtained, together with considerable low $f s w$ values. These include, in ascending order of score: (i) "21.Participation in and opportunities for recreation/leisure activities"; (ii) "18.Financial resources"; and (iii) "15.Sexual activity". These results suggest the development of community events that facilitate involvement in leisure and recreational activities, including those that promote health among the elderly population, particularly physical activities, as proposed in (Paiva, Pegorari, Nascimento, \& Santos, 2016). Such actions are considered important, as they promote social interactions and effective participation in society, making it possible to maintain the functional and/or cognitive abilities of elderly individuals and therefore providing them with greater and long-lasting independence. The most negative perception by the respondents regarding facet "18.Financial resources" was associated with the fact that the vast majority (75.2\%) were "Retired", earning low incomes (pensions). This issue should not be neglected in the assessment of QOL, because financial difficulties may result in a loss of healthy life years, having a similar weight as the presence of chronic diseases, as suggested by (66). Conversely, the facet " 17 .Home environment" had the highest score of all 24 of the Portuguese WHOQOL-BREF, which seems to suggest that the elderly greatly appreciate their homes and thus wish to remain where they lived; a similar suggestion was found in (25). Finally, in relation to social relations, we believe that it is extremely important to highlight the geographical isolation in which these elderly people live, which can be further restrictive when taking into account the very low population density, the existing difficulties of travelling due to the scarcity of a public transportation network in the area, and the physical limitations of these individuals.

Regarding the QOL scores, men showed better QOL in all domains than women, with significant differences in the Physical Health and Psychological domains. This result is likely associated with a greater predisposition of women to physical and mental problems compared with men, indicating a greater difficulty in accepting aging and resulting in a more negative QOL assessment, as has been suggested in several studies (22), (52), (67), (68). Other studies report that long-lived women exhibit more limitations and a greater loss of functional capacity as a result of a higher prevalence of chronic diseases, with negative impacts on the QOL in both of the 
mentioned domains (69), (51). Regarding both genders, QOL varied negatively with increasing age (i.e., a negative association was observed in all domains), which may be related to an increased overall burden of disease as a person ages, thus resulting in a decline in health (70). QOL appears to decrease significantly as a function of marital status when comparing people who are married/living as married with widowed (mostly women) individuals, a finding similar to (71) and (72). These authors claimed that the loss of a partner can lead to demotivation to self-care and thus to a lower QOL. Several studies have found that the most important factor for successful aging is the quality of a person's relationships, namely, intimate relationships (62). Health professionals may contribute significantly to the development of interventions to help minimize such feelings. The mean QOL scores varied with education, with the highest scores obtained for the highest educational levels in all domains and in the GHF, and the lowest were obtained for those who were illiterate. These results indicated a low educational level of the respondents: nearly half had no education, and $29.6 \%$ were illiterate (mostly women)-two serious problems in Portuguese rural society that affect women at a greater extend. This finding is in line with the results of (73). It was observed that older women have less education, fostering illiteracy in this population group. As reported in (74), it is assumed that a higher level of education may contribute to higher levels of literacy, promoting better knowledge of multiple and complex chronic diseases and empowering people to better manage their health issues. Literacy seemed to be associated with a better QOL, which may empower an individual to obtain, process, understand, and use basic information about health and the available services, thus increasing their capability to manage their health/disease processes, as stated in (75).

In relation to QOL domains, $f s w$ can also be used to compute the average domain score of a particular individual. For example, let us suppose an individual with the following answers to the Social Relationships domain: (i) F13.3="3"; (ii) F14.4="2"; (iii) F15.3="4". According to the WHOQOL group, the score for this person in this domain is the average of the three points of the Likert scale: $((3+2+4)-3) / 12 ' 100 \%=50.0 \%$ (on a scale ranging from 0 to $100 \%)$. However, using the respective $f s w$ value (see the respective values in Table 4): (i) $f S W_{F 13.3}=0.094$; (ii) $f S W_{F 14.4}=0.078$; and (iii) $f S W_{F 15.3}=0.054$, which can be normalized into 1.0, respectively: (i) $f S W_{F 13.3}=0.398$; (ii) $f S W_{F 14.4}=0.331$; and (iii) $f S W_{F 15.3}=0.271$, and used to compute another average score according to: $\left(3^{\prime} 0.398+2^{\prime} 0.331+4^{\prime} 0.271\right) / 5^{\prime} 100 \%=58.8 \%$. The difference between the two averages is $8.8 \%$, raising some questions: What is the most correct average score for the person in relation to the "Social Relationships" domain-50.0\% or $58.8 \%$ ? How should the QOL domain average be computed: using the WHOQOL standards or based on the $f s w$ ? It is not easy to answer these questions, and only a group of specialists in several health areas can give an answer. Therefore we believe that further research should be carried out on this topic.

The QOL decreased significantly in the Physical Health and Environment domains as people aged, which is in line with previous studies, such as (48) and (76). However, not all studies have confirm this decrease trend between QOL as people age, for example the findings of (77), a study that involved 20 countries. The decrease in QOL as people age appears to be more likely a result of chronic diseases in the elderly population (42).

Regarding the possible biological and sociodemographic factors that could be predictive of QOL domains, the results of the block linear regression models suggested that QOL increased significantly with education in all domains (reinforcing what was observed in this paper in relation to literacy) and with gender in the Physical Health and Psychological domains. Moreover, QOL increased significantly in with marital status in the

Page $14 / 30$ 
Psychological and Social Relationships domains, suggesting that older people living with their spouses lead to a more positive impact on the QOL, as this contributes to the stability of their relationships and promote wellbeing. These results show some similarity with those published by (48) and (78).

Regarding the QOL domains identified as possible predictors of GHF, the results (in decreasing order of explained variance) suggested that only the Physical Health (explaining more than five percent of the variance), Psychological, and Environment domains were statistically significant in the developed MLR model, with the first two presenting the greatest importance. This finding corroborated (22), which may suggest that QOL is sensitive to changes in physical health, as stated by (30).

Regarding the question "Are you currently ill?", we observed that the respondents tended to answered "Yes" due to a worsening of their health condition, thus leading to a negative perception of their QOL, with a higher level of dependence and greater difficulty in managing their health process (25). Respondents who answered "No" did not show a worsening of their health condition, although they presented similar chronic diseases. Therefore, the answers to this question on Portuguese WHOQOL-BREF seem to suggest that lower QOL scores may not be associated with the individual's multimorbidity but rather with the fact that they feel sick, usually due to a worsening of their health condition (generating dependency and limitations). Indeed, this question that indicates a self-expectation of health may be strongly a possible predictive of QOL and other well-being outcomes in older adults (30). Consequently, the implementation of strategies to promote self-care and to prevent the worsening of health conditions and subsequent disabilities should be encouraged, which is aligned with the recommendations in (25) and (53).

\section{Conclusions}

In conclusion, this paper describes the QOL profile of elderly citizens residing in an inland region located in the middle-south of the Portugal main territory, which has a large geographic area and, simultaneously, a low population density.

This QOL profile is composed of several items based on the Portuguese WHOQOL-BREF, described as follows: (i) Regarding Biological and Sociodemographic characteristics, the number of women was greater than men, with illiteracy found in almost one third of the sample (the majority being women); nearly half of the sample never went to school (also the majority being women); (iia) The most important facets of the CFA model (presenting higher fsw values) were "Activities of daily living", "Work capacity", "Self-esteem", and "Opportunities for acquiring new information and skills". This indicates that the study participants had selfconfidence, and despite their advanced aged they searched for opportunities to continue with work and to explore new opportunities and learn new skills; (iib) In relation to the average score facets, higher values were related to the home environment, which means that the participants preferred to stay in their homes, even when they presented some disabilities and they would like to stay connected with their physical environment as well as maintain their personal relationships and social support; (iii) Men consistently presented greater QOL scores in all domains compared to women; (iv) QOL scores in all domains decreased as people aged, although this was more pronounced in men; (v) regarding possible biological and sociodemographic predictors of QOL domains, the education level was significant in all domains, i.e., as education levels increased, the QOL increased, while it was significant only in the Psychological and Social Relationships domains, representing an increase in the respective scores; (vi) in relation to the GHF, the Physical Health and Psychological domains 
were the most important possible predictors of GHF, followed the Environment domain (with half of the importance of the former two domains), and Social Relationships was considered to be not important in the model. Finally, it was found that a self-expectation of health may be strongly possible predictive of QOL and other well-being outcomes in older adults when considering the question "Are you currently ill?".

The high illiteracy rate must be emphasized (mostly related to the older age group of women) along with the very low population density in the large study area, forcing the residents to travel long distances in a region with a limited public transportation network. This situation leads to those with an advanced age (an important proportion of participants in the oldest age group) becoming isolated and lonely, facts that contribute (among others) to the high suicide rate. The lack of opportunities to acquire new skills and work, among other dimensions, are considered general characteristics of rural areas. Fig. 4 summarizes the rural dimensions presented in Portugal's main territory in comparison to those of the coastal areas.

The authors of this research believe that the information extracted from the proposed QOL profile constitutes an important empirical basis that allows for more a detailed assessment of the concrete health care needs of the elderly population. This information can lead to the concise planning and monitoring of health interventions and health policies management, extending the current general knowledge of QOL. With this QOL profile, which had not yet been carried out for the elderly population residing in RBA, the authors expected "to find out what is really important to elderly individuals".

\section{Limitations}

This study presents the following limitations. Most importantly was the low number of respondents (351, although 468 were expected), especially due the low level of participation of some health professionals. Since this study has focused on a particular region of Portugal's main territory that presents special demographic and geographic characteristics, the results may not be generalizable to other regions or even to the entire country. Due to the lack of official QOL cutoff points, it was not possible to work with a quantitative QOL scale, which does not allow the use of a qualitative evaluation, such as "Good" or "Poor", as in the case of the International Classification of Functioning, Disability and Health (ICF).

\section{Declarations}

\section{Ethics approval and consent to participate}

The Ethical Committee that evaluates whether the study is properly designed and performed, namely, the Institutional Review Board of ULSBA (IRB-ULSBA), approved the study protocol, study design, how the interviews would be conducted, and the informed consent.

\section{Consent to publish}

Informed consent was correctly obtained from all of the 351 participants.

\section{Availability of data and materials}


All data and material available in this paper can be acquired by contacting the author: Henrique Oliveira (hjmo@lx.it.pt)

\section{Competing interests}

The authors declare that they have no conflicts of interest.

\section{Funding}

This work was funded by the 4IE project (0045-4IE-4-P), which was funded by the Interreg V-A España-Portugal (POCTEP) 2014-2020 program (https://4ie.eu/).

\section{Authors' contributions}

Margarida Goes conceived the study in the scope of her PhD Nursing studies, supervised by Manuel José Lopes and Henrique Oliveira. César Fonseca contributed to the access and revision of data about aging. Henrique Oliveira and João Marôco contributed to the conception of all the statistical analysis methods developed in this paper. João Marôco was the senior guarantor of the accuracy of the data analysis. All authors drafted and revised the manuscript for important intellectual content and approved the manuscript. Margarida Goes and Henrique Oliveira take responsibility for data integrity while Henrique Oliveira is the guarantor.

\section{Acknowledgements}

The authors acknowledge all the support given by the health professionals that collaborated in the data acquisition, especially in conducting the participant interviews, as well as the professional support provided by the ULSBA primary health care teams (http://www.ulsba.min-saude.pt/).

\section{References}


1. César F. Modelo de autocuidado para pessoas com 65 e mais anos de idade, necessidades de cuidados de enfermagem. Tese de Doutoramento. Lisboa: Universidade de Lisboa, Enfermagem; 2014.

2. PORDATA. Ageing index. [Online].; 2016 [cited 2018 April 14. Available from: https://www.pordata.pt/en/Europe/Ageing+index-1609.

3. INE. Projections of resident population in Portugal 2015 and 2080. [Online].; 2017 [cited 2018 April 12. Available from: https://www.ine.pt/xportal/xmain? xpid=INE\&xpgid=ine_destaques\&DESTAQUESdest_boui=277695619\&DESTAQUESmodo=2\&xlang=en.

4. SNS. Serviço Nacional de Saúde - SNS. [Online].; 2019 [cited 2019 August 20. Available from: https://www.sns.gov.pt/institucional/entidades-de-saude/.

5. ULSBA. Unidade Local de Saúde do Baixo Alentejo. [Online].; 2014 [cited 2018 November 10. Available from: http://www.ulsba.min-saude.pt/.

6. Goes M, Oliveira H, Lopes M. Spatial analysis techniques applied to the characterization of elderly population for the planning of nursing care. Revista Ibero-Americana de Saúde e Envelhecimento. 2016; 2(3).

7. INE. Population's density (No./ $\mathrm{km}^{2}$ ) by Place of residence (at the date of Census 2011). [Online].; 2011 [cited 2018 October 27. Available from:

https://www.ine.pt/clientFiles/u8UAEMmQgvkfhvysgNncw0DL_15245.xls.

8. INE. Statistics Portugal. [Online].; 2017 [cited 2018 April 12. Available from:

https://www.ine.pt/clientFiles/ZABbysovUAa8_SgERrcmeKpY_23158.xls.

9. INE - Statistics Portugal. INE - Statistics Portugal. [Online].; 2017 [cited 2019 August 2019. Available from: https://www.ine.pt/clientFiles/ejrCqJEFOvqAf_a5PIBGAllc6aGSrhCRIseRQ5od_67253.xls.

10. Nunes A. Suicídio em Portugal: um retrato do país. Jornal Brasileiro de Psiquiatria. 2018; 67: p. 25-33.

11. RBA-ULSBA, ECCI. ULSBA - Unidade Local de Saúde do Baixo Alentejo. [Online].; 2019 [cited 2019 August 20. Available from: http://www.ulsba.min-saude.pt/category/servicos/cuidados-continuadosintegrados/.

12. RBA. From Wikipedia, the free encyclopedia. [Online].; 2019 [cited 2019 August 20. Available from: https://en.wikipedia.org/wiki/Baixo_Alentejo_(intermunicipal_community).

13. PORDATA. PORDATA: Base de Dados de Portugal Contemporâneo. [Online].; 2011-2017 [cited 2019 August 20. Available from:

https://www.pordata.pt/en/DB/Municipalities/Search+Environment/Table/5797422.

14. Gruneir A, Silver M, Rochon P. Emergency Department Use by Older Adults: A Literature Review on Trends, Appropriateness, and Consequences of Unmet Health Care Needs. Journal of Medical Care Research and Review. 2011;: p. 131-155.

15. DGS. Direcção Geral de Saúde. [Online].; 2018 [cited 2019 January 15. Available from:

https://www.sns.gov.pt/wp-content/uploads/2018/04/PortugalReviewReport_Printers_03April20182.pdf.

16. Barreto M, Carreira L, Marcon S. Envelhecimento populacional e doenças crônicas: Reflexões sobre os desafios para o Sistema de Saúde Pública. Revista Kairós Gerontologia. 2015 Janeiro-Março; 18(1): p. 325-339.

17. Fleck MP. Problemas conceituais em qualidade de vida. In FlecK MP, \& C. A Avaliação de Qualidade de Vida - Guia para Profissionais da Saúde. Porto Alegre: ARTMED S.A.; 2008. p. 19-28.

18. Zhang L, Zhang J. Impacts of Leisure and Tourism on the Elderly'slmpacts of Leisure and Tourism on the Elderly's. MDPI - Sustainability. 2018;: p. 1-17. 
19. Ottati F, Souza Campos. Qualidade de vida e estratégias de enfrentamento de pacientes em

tratamento oncológico. Acta Colombiana de Psicología. 2017 Julho-Dezembro; 17(2): p. 103-111.

20. WHOQOL Portuguese Team. Relationships, Development and Health. [Online].; 2006 [cited 2019 August 10th. Available from: http://www.fpce.uc.pt/saude/projeto15.html.

21. Canavarro M, Serra A, Simões $M$, Gameiro M, Quartilho M, Rijo D, et al. WHOQOL-Bref (Versão em Português de Portugal do Instrumento Abreviado de Avaliação da Qualidade de Vida da Organização Mundial de Saúde). [Online].; 2006 [cited 2018 Abril 15. Available from:

http://www.fpce.uc.pt/saude/WHOQOL_Bref.html.

22. Canavarro $M$, Serra A, Pereira $M$, Simões $M$, Quartilho $M$, Rijo D, et al. WHOQOL disponível para Portugal: Desenvolvimento dos instrumentos de Avaliação da Qialidade de Vida da Organização Mundial de Saúde (WHOQOL-100 e WHOQOL-BREF). In Canavarro MC, Serra AV, editors. Qualidade de vida e saúde: Uma abordagem na perspectiva da Organização Mundial de Saúde. Lisboa: Fundação Calouste Gulbenkian; 2010. p. 171-190.

23. Angelim R, Figueiredo T, Correia P, Bezerra S, Baptista R, Abrão F. Análise da Qualidade de Vida por meio do WHOQOL: Análise bibliométrica da produção de Enfermagem. Revista Baiana de Enfermagem. 2015; 29(4).

24. Fougère $B$, Aubertin-Leheudre $M$, Vellas $B$, Andrieu $S$, Demougeot $L$, Cluzan $C$, et al. Clinical research for older adults in rural areas: the MINDED study experiance. AGE (American Aging Association). 2016; 38(2): p. 4.

25. Tavares D, Santos L, Dias F, Ferreira P, Oliveira E. Quality of life of rural elderly and associated factors. Journal of Nursing - UFPE On Line. 2015; 9(11): p. 9679-9687.

26. Durgawale P, Shinde M, Samue-Murugajothy G. Study of Assessment of Quality of Life in Elderly Residing in Rural Area. International Journal of Science and Research (IJSR). 2014; 3(10): p. 12911294.

27. Garbaccio J, Tonaco L, Estêvão W, Barcelos B. Aging and quality of life of elderly people in rural areas. Revista Brasileira de Enfermagem. 2018; 71(suppl2 [Thematic Issue: Health of the Elderly]): p. 724-32.

28. Karamivand V, Bastani F, Haghani H. Supportive needs of urban and rural elders. Journal of Aging and Geriatric Psychiatry. 2018; 2(2): p. 1-6.

29. Conde-Sala J, Portellano-Ortiz C, Calvó-Perxas L, Garre-Olmo j. Quality of life in people aged 65+ in Europe: associated factors and models of social welfare-analysis of data from the SHARE project (Wave 5). Quality of life research. 2017;: p. 1059-1070.

30. Brett C, Dykiert D, Starr J, Deary I. Predicting change in quality of life from age 79 to 90 in the Lothian Birth Cohort 1921. Quality of life research. 2018;: p. 1-13.

31. Mota-Pinto A, Rodrigues V, Botelho A, Veríssimo M, Morais A, Alves $C$, et al. A socio-demographic study of aging in the Portuguese population: The EPEPP study. Archives of Gerontology and Geriatrics. 2010;: p. 1-5.

32. Fonseca A, Paúl C, Martin I, Amado J. Condição psicossocial de idosos rurais numa aldeia do interior de Portugal. In Paúl C, Fonseca A. Envelhecer em Portugal: Psicologia, saúde e prestação de cuidados. Lisbon: Climepsi Editores; 2005. p. 97-108.

33. Pimentel L, Albuquerque C. Solidariedades Familiares e o Apoio a Idosos. Limites e Implicações. Textos \& Contextos (Porto Alegre). 2010; 9(2): p. 251-263.

34. Azeredo Z, Afonso M. Loneliness from the perspective of the elderly. Revista Brasileira de Geriatria e Gerontologia. 2016;: p. 313-324.

35. Thadathil S, Jose R, Varghese S. Assessment of Domain wise Quality of Life Among Elderly Population Using WHO-BREF Scale and its Determinants in a Rural Setting of Kerala. International Journal of Current Medical And Applied Sciences. 2015 June; 7(1): p. 43-46. 
36. Brandão D, Ribeiro O, Paúl C. Functional, Sensorial, Mobility and Communication Difficulties in the Portuguese Oldest Old (80+). Acta Médica Portuguesa - Revista Científica da Ordem dos Médicos. 2017; 30(6): p. 463-471.

37. Kaholokula J, Haynes S, Grandinetti A, Chang H. Biological, Psychosocial, and Sociodemographic Variables Associated With Depressive Symptoms in Persons With Type 2 Diabetes. J Behav Med. 2003; 26(5): p. 435-58.

38. Mhaka-Mutepfa M. Sociodemographic Factors and Health-Related Characteristics That Influence the Quality of Life of Grandparent Caregivers in Zimbabwe. SGS - Gerontology and Geriatrics. 2018;: p. 111.

39. Patsou E, Alexias G, Anagnostopoulos F, Karamouzis V. DOVEPRESS - open access to scientific and medical research. [Online].; 2018 [cited 2019 January 15. Available from:

https://www.dovepress.com/physical-activity-and-sociodemographic-variables-related-to-global-heapeer-reviewed-fulltext-article-PRBM.

40. Caron J, Mercier C, Diaz P, Martin A. Socio-demographic and clinical predictors of quality of life in patients with schizophrenia or schizo-affective disorder. Quality of life research. 2005;: p. 203-213.

41. Khan A, Tahir I. Influence of Social Factors to the Quality of Life of the Elderly in Malaysia. Open Medicine Journal. 2014; 1: p. 29-35.

42. Raggi A, Corso B, Minicuci N, et a. Determinants of Quality of Life in Ageing Populations: Results from a Cross-Sectional Populations: Results from a Cross-Sectional. PLoS One. 2016; 11(7).

43. Soósová M. Determinants of quality of life in elderly. Central European Journal of Nursing and Midwifery. 2016; 7(3): p. 484-493.

44. Scheaffer R, Mendenhall W, Ott R, Gerow K. Elementary Survey Samplig - seventth edition: Brooks/Cole; 2012.

45. Oliveira A. Bioestatística Descodificada: Bioestatística, Epidemiologia e Investigação Lisboa: Lidel edições técnicas, Ida.; 2014.

46. Vilar M, Sousa L, Simões M. The European Portuguese WHOQOL-OLD module and the new facet Family/Family life: realiability and validity studies. Quality of life research. 2016; 25: p. 2367-2372.

47. Marôco J. Análise de equações estruturais: Fundamentos teóricos, software e aplicações. 2nd ed. Pêro Pinheiro: http://www.reportnumber.pt/public.html; 2014.

48. Gameiro S, Canavarro M, Pereira M, Serra A, Carona T, Carona C, et al. Factores sociais e demográficos de variabilidade da qualidade de vida na população geral. In Canavarro M, Serra A. Qualidade de Vida e Saúde: Uma abordagem na perspectiva da organização mundial de saúde. Lisbon: Fundação Calouste Gulbenkian; 2010. p. 251-268.

49. Fleck MP. A avaliação da Qualidade de Vida: Guia para profissionais da saúde São Paulo: ARTMED EDITORA; 2008.

50. UCLA. Institute for Digital Research \& Education. [Online].; 2019 [cited 2019 August 14. Available from: https://stats.idre.ucla.edu/spss/faq/what-does-cronbachs-alpha-mean/.

51. Lopes M, Escoval A, Pereira D, Pereira C, Carvalho C, Fonseca C. Evaluation of elderly persons' functionality and care needs. Revista Latino-Americana de Enfermagem. 2013 Janeiro-Fevereiro; 21(9).

52. Rodrigues L, Tavares D, Dias F, Pegorari M, Marchiori G, Tavares D. Quality of life of elderly people of the community and associated factors. Journal of Nursing UFPE. 2017; 11(3).

53. Paiva $\mathrm{M}$, Pegorari $\mathrm{M}$, Nascimento J, Santos Á. Fatores associados à qualidade de vida de idosos comunitários. Ciência \& Saúde Coletiva. 2016 Novembro; 21(11). 
54. Nicodemo D, Godoi MP. Juventude dos anos 60-70 e envelhecimento: estudo de casos sobre. Revista Ciência em Extensão. 2010; 6(1): p. 40-53.

55. Bicudo M. Do envelhecimento saudável à longevidade com qualidade: Contributo dos Enfermeiros. In Lopes M. O cuidado de Enfermagem à pessoa idosa. Loures: Lusociência; 2013. p. 39-74.

56. Jagger C, Reyes-Beaman S. Monitoring Health by Healthy Active Life Expectancy-A User's Guide: Department of Epidemiology and Public Health University of Leicester; 2003.

57. Jagger C, Matthews FE, Wohland P, Fouweather T, Stephan BCM, Robinson L, et al. A comparison of health expectancies over two decades in England: results of the Cognitive Function and Ageing Study I and II. The Lancet. 2016; 387(10020): p. 779-786.

58. Kingston A, Wohland P, Wittenberg R, Robinson L, Brayne C, Matthews FE, et al. Is late-life dependency increasing or not? A comparison of the Cognitive Function and Ageing Studies (CFAS). The Lancet. 2017; 390(10103): p. 1676-1684.

59. Kingston A, Robinson L, Booth $\mathrm{H}$, Knapp M, Jagger C. Projections of multi-morbidity in the older population in England to 2035: estimates from the Population Ageing and Care Simulation (PACSim) model. Age and Ageing. 2018; 47(3): p. 374-380.

60. Oliveira AR. A cada um o seu lugar, a política feminina do Estado Novo. e-Cadernos CES. 2011;: p. 215-217.

61. Bozkurt, Yılmaz. The Determination of Functional Independence and Quality of Life of Older Adults in a Nursing Home. International Journal of Caring Sciences. 2016;: p. 198-210.

62. Hitchcott P, Fastame M, Ferrai J, Penna M. PsychologicalWell-Being in Italian Families: An Exploratory Approach to the Study of Mental Health Across the Adult Life Span in the Blue Zone. Europe's Journal of Psychology. 2017; 13(3): p. 441-454.

63. NORC at the University of Chicago. Perceptions of aging during each decade of life after 30 . West Health Institute/NORC Survey on Aging in America. 2017;: p. 1-10.

64. Quine S, Morrell S. Fear of loss of independence and nursing home admission in older Australians. Health and Social Care in the Community. 2007; 15(3): p. 212-220.

65. Tavares D, Matia T, Ferreira P, Pegorari M, Nascimento J, Paiva M. Qualidade de vida e autoestima de idosos na comunidade. Ciência \& Saúde Coletiva. 2016; 21(11): p. 3557-3564.

66. Stringhini S, et al. Socioeconomic status, non-communicable disease risk factors, and walking speed in older adults: multi-cohort population based study. British Medical Journal. 2018 Março 23.

67. Pereira R, Cotta R, Franceschini S, Ribeiro R, Sampaio R, Priore S, et al. Contribuição dos domínios físico, social, psicológico e ambiental para a qualidade de vida global de idosos. Contribuição dos domínios físico, social. 2006 Janeiro-Abril; 28(1): p. 27-38.

68. Almeida-Brasil C, Silveira M, Silva K, Lima M, Faria, Cardoso C, et al. Qualidade de vida e características associadas: aplicação do WHOQOL-BREF no contexto da Atenção Primária à Saúde. Ciência \& Saúde Coletiva. 2017; 22(5): p. 1705-1716.

69. Nunes M, Ribeiro R, Rosado L, Franceschini S. Influência das características sociodemográficas e epidemiológicas na capacidade funcional de idosos residentes em Ubá, Minas Gerais. Revista Brasileira de Fisioterapia. 2009 Setembro-Outubro; 13(5).

70. WHO. Global Health and Aging. NIH Publication no. 11-7737: National Institute on Aging, National Institutes of Health; 2011.

71. Vagetti G, Filho V, Moreira N, Oliveira V, Mazzardo O, Campos W. Condições de saúde e variáveis sociodemográficas associadas à qualidade de vida em idosas de um programa de atividade física de Curitiba, Paraná, Sul do Brasil. Cadernos de Saúde Pública. 2013 Maio; 29(5).

72. Arslantas D, Ünsal, Metintas S, Koc F, Arslantas A. Life quality and daily life activities of elderly 
people in rural areas, Eskişehir (Turkey). Archives of Gerontology and Geriatrics. 2009 Março-Abril; 48(2): p. 127-131.

73. Soares M, Tavares D, Dias F, Diniz M, Geib S. Morbidades, capacidade funcional e qualidade de vida de mulheres idosas. Escola Anna Nery. 2010 Outubro-Novembro; 14(4).

74. Artacho R, Lijano C, Sanchez-Vico AB, Vargas Sanchez C, Gonzalez Calvo J, Bouzas PR, et al. Nutritional status in chronically-ill elderly patients. Is it related to quality of life? Journal of nutrition, health \& aging. 2014 Fevereiro; 18(2): p. 192-197.

75. Loureiro L, Mendes A, Barroso T, Santos J, Santos J, Oliveira R, et al. Literacia em saúde mental de adolescentes e jovens: conceitos e desafios. Revista de Enfermagem Referência. 2012 Março; III(6).

76. Parker L, Moran G, Roberts L, Calvert M, McCahon D. The burden of common chronic disease on health-related quality of life in an elderly community dwelling population in the UK. Family Practice. 2014; 31(5): p. 557-563.

77. Low G, Molzahn A, Schopflocher D. Attitudes to aging mediate the relationship between older peoples' subjective health and quality of life in 20 countries. BMC - Health and Quality of Life Outcomes. 2013; 11.

78. Shrestha $\mathrm{M}, \mathrm{KC} \mathrm{H}$, Bhattarai P, Mishra A, Parajuli S. Quality of life of elderly people living with family and in old age home in Morang District, Nepal. BIBECHANA: A multidisciplinary journal of Science, Technology and Mathematics. 2018; 16(2019): p. 221-227.

79. Portuguese Government. O interior em números - Bases para um diagnóstico. ; 2016.

80. Marôco J. Análise Estatística com o SPSS Statistics, $5^{\text {a }}$ Edição. 6th ed. Pero Pinheiro: ReportNumber; 2011.

\section{Tables}

Table 1. Biological and sociodemographic characteristics of the 351 respondents residing in RBA.

\begin{tabular}{|c|c|c|}
\hline Variables & $n$ & $\%$ \\
\hline \multicolumn{3}{|l|}{ Gender: } \\
\hline Male & 163 & 46.4 \\
\hline Female & 188 & 53.6 \\
\hline \multicolumn{3}{|l|}{ Age group: } \\
\hline $65-74$ & 132 & 37.6 \\
\hline $75-84$ & 135 & 38.5 \\
\hline 85 and higher & 84 & 23.9 \\
\hline \multicolumn{3}{|l|}{ Marital status: } \\
\hline Single/Divorced/Separated & 31 & 8.8 \\
\hline Married/Living as Married & 206 & 58.7 \\
\hline Widowed & 114 & 32.5 \\
\hline \multicolumn{3}{|l|}{ Educational level: } \\
\hline Does not know how to read or wr & e104 & 29.6 \\
\hline Knows how to read and/or write & 59 & 16.8 \\
\hline $1^{\text {st }}-4^{\text {th }}$ grade & 165 & 47.0 \\
\hline More education & 23 & 6.6 \\
\hline
\end{tabular}

Table 2. Results of indexes for the initial and adjusted CFA models. 
Indexes Initial ModelAdjusted ModelQualitative classification*

\begin{tabular}{llll}
\hline & 3.224 & 2.467 & Good \\
CFI & 0.866 & 0.913 & Good \\
GFI & 0.832 & 0.871 & Poor \\
TLI & 0.850 & 0.901 & Good \\
\hline SRMR & 0.0641 & 0.0599 & Acceptable \\
RMSEA & 0.080 & 0.065 & Acceptable \\
PCLOSE & $<0.001$ & $<0.001$ & - \\
\hline
\end{tabular}

* Accordingly to (47)

Table 3. Composite reliability and convergent validity results for the adjusted CFA model.

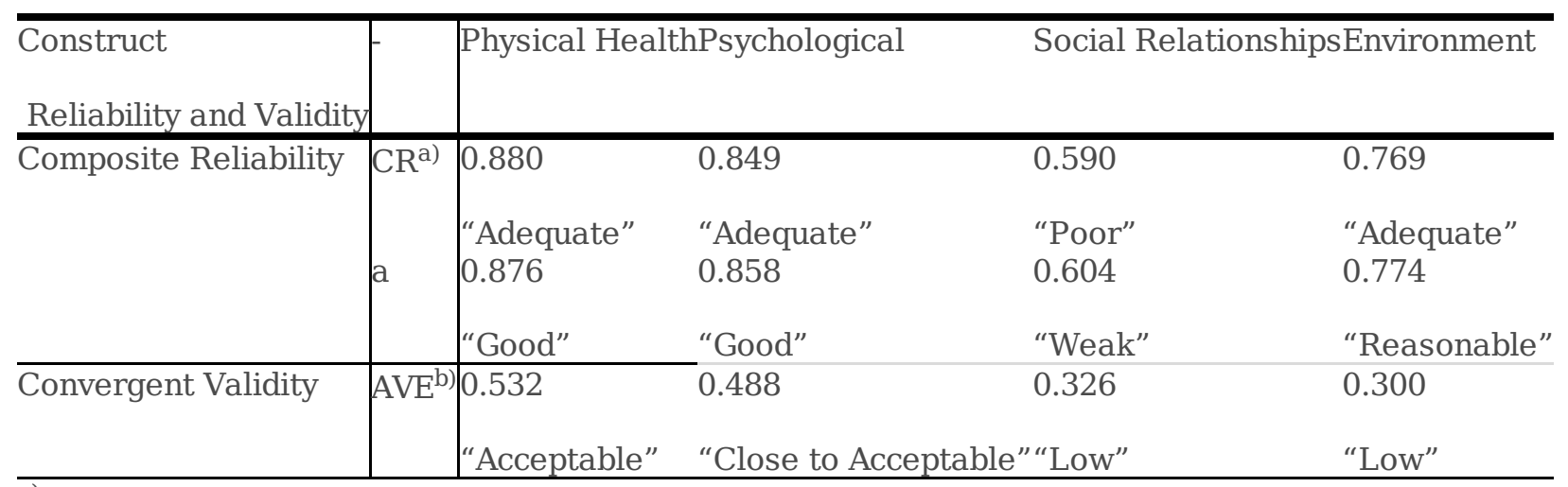

a) "Adequate" when $\mathrm{CR}>0.7$ see (47)

b) "Acceptable" when AVE>0.5 see (47)

Table 4. Most valued facets in the estimation of each QOL domain score. Only those with $f s w$ values greater than 0.05 are shown. The Portuguese WHOQOL-BREF number of the facet is also indicated. 


\begin{tabular}{|c|c|c|c|}
\hline Domain & Facet & $\begin{array}{l}\text { Factor score } \\
\text { weights } \\
(f S w)\end{array}$ & $\begin{array}{l}\text { Mean } \\
\text { (Likert } \\
\text { scale) }\end{array}$ \\
\hline \multirow[t]{4}{*}{ Physical Health } & 10. Activities of daily living & 0.276 & 3.27 \\
\hline & 12. Work capacity & 0.213 & 3.19 \\
\hline & 2. Energy and fatigue & 0.084 & 3.16 \\
\hline & 9. Mobility & 0.071 & 3.36 \\
\hline \multirow[t]{5}{*}{ Psychological } & 6. Self-esteem & 0.210 & 3.48 \\
\hline & 7. Bodily image and appearance & 0.081 & 3.33 \\
\hline & 5. Thinking, learning, memory and concentration & 0.079 & 3.44 \\
\hline & 4. Positive feelings & 0.072 & 3.50 \\
\hline & 24. Spirituality/Religion/Personal beliefs & 0.057 & 3.50 \\
\hline Social & 13. Personal relationships & 0.094 & 3.77 \\
\hline \multirow[t]{2}{*}{ Relationships } & 14. Social support & 0.078 & 3.62 \\
\hline & 15. Sexual activity & 0.064 & 2.92 \\
\hline \multirow[t]{8}{*}{ Environment } & 20. Opportunities for acquiring new information and skills & 0.124 & 3.17 \\
\hline & 17. Home environment & 0.082 & 3.83 \\
\hline & 22. Physical environment (pollution/noise/traffic/climate) & 0.062 & 3.72 \\
\hline & $\begin{array}{l}\text { 21. Participation in and opportunities for recreation/leisure } \\
\text { activities }\end{array}$ & 0.052 & 2.74 \\
\hline & 23. How satisfied are you with your transport? & 0.044 & 3.40 \\
\hline & 19. How satisfied are you with your access to health services? & 0.038 & 3.67 \\
\hline & 16. How safe do you feel in your daily life? & 0.032 & 3.52 \\
\hline & 18. Financial resources & 0.016 & 2.87 \\
\hline
\end{tabular}

Table 5. Mean score variations for the four QOL domains and the GHF for the entire sample.

\begin{tabular}{llllll}
\hline \multirow{2}{*}{ Variables and Statistical Tests Domains } & & \multicolumn{3}{c}{ GHF } \\
\cline { 2 - 5 } & \multicolumn{2}{l}{ Physical HealthPsychologicalSocial } & RelationshipsEnvironment \\
\hline Mean & 56.3 & 59.8 & 61.0 & 59.1 & 51.4 \\
SD & 19.54 & 16.95 & 13.92 & 13.16 & 20.84
\end{tabular}

Table 6. Mean score variations for the four QOL domains and the GHF, stratified by gender, age group, marital status, and education level. For age group, marital status, and education level, scores are based on ranks. 


\begin{tabular}{|c|c|c|c|c|c|}
\hline \multirow[t]{2}{*}{ Variables and Statistical Tests } & \multicolumn{4}{|l|}{ Domains } & \multirow[t]{2}{*}{ GHF } \\
\hline & Physical Health & Psychological & $\begin{array}{l}\text { Social } \\
\text { Relationships }\end{array}$ & Environment & \\
\hline \multicolumn{6}{|l|}{ Gender. } \\
\hline \multirow[t]{2}{*}{ Male } & 60.7 & 62.7 & 61.8 & 60.1 & 53.5 \\
\hline & 19.89 & 17.11 & 13.76 & 13.62 & 21.26 \\
\hline \multirow[t]{2}{*}{ Female } & 52.6 & 57.3 & 60.2 & 58.3 & 49.6 \\
\hline & 18.48 & 16.47 & 14.05 & 12.72 & 20.35 \\
\hline Student's $t$-test & $\mathrm{t}=3.937 \mathrm{p}<0.001$ & $\mathrm{t}=2.976 \mathrm{p}=0.003$ & $\mathrm{t}=1.056 \mathrm{p}=0.291$ & $\mathrm{t}=1.232 \mathrm{p}=0.219$ & $\mathrm{t}=1.731 \mathrm{p}=0.084$ \\
\hline \multicolumn{6}{|l|}{ Age group: } \\
\hline 65 to 74 years & 211.31 & 203.06 & 199.73 & 207.69 & 199.03 \\
\hline 75 to 84 years & 152.17 & 160.99 & 164.12 & 164.04 & 157.05 \\
\hline 85 and older & 158.80 & 157.61 & 157.80 & 145.42 & 170.26 \\
\hline Kruskal-Wallis H & $\begin{array}{l}\mathrm{H}(2)=25.924 \\
\mathrm{p}<0.001\end{array}$ & $\begin{array}{l}H(2)=15.193 \\
p=0.001\end{array}$ & $\begin{array}{l}\mathrm{H}(2)=12.294 \\
\mathrm{p}=0.002\end{array}$ & $\begin{array}{l}\mathrm{H}(2)=22.515 \\
\mathrm{p}<0.001\end{array}$ & $\begin{array}{l}\mathrm{H}(2)=12.160 \\
\mathrm{p}=0.002\end{array}$ \\
\hline \multicolumn{6}{|l|}{ Marital status: } \\
\hline Single/Divorced/ Separated & 180.13 & 147.48 & 156.31 & 157.76 & 172.97 \\
\hline Married/Living as married & 188.40 & 196.15 & 189.45 & 188.89 & 181.11 \\
\hline Widowed & 152.40 & 147.35 & 157.05 & 157.50 & 167.60 \\
\hline Kruskal-Wallis H & $\begin{array}{l}H(2)=9.339 \\
p=0.009\end{array}$ & $\begin{array}{l}\mathrm{H}(2)=19.777 \\
\mathrm{p}<0.001\end{array}$ & $\begin{array}{l}H(2)=9.153 \\
p=0.010\end{array}$ & $\begin{array}{l}H(2)=8.125 \\
p=0.016\end{array}$ & $\begin{array}{l}H(2)=1.374 \\
p=0.503\end{array}$ \\
\hline \multicolumn{6}{|l|}{ Educational level: } \\
\hline $\begin{array}{l}\text { Does not know how to read } \\
\text { or write }\end{array}$ & 133.02 & 133.46 & 136.69 & 134.14 & 155.01 \\
\hline $\begin{array}{l}\text { Knows how to read and/or } \\
\text { write }\end{array}$ & 174.79 & 148.62 & 169.20 & 171.84 & 163.21 \\
\hline $1^{\text {st }}-4^{\text {th }}$ grade & 193.78 & 201.45 & 192.52 & 193.49 & 185.40 \\
\hline More education & 245.91 & 256.02 & 252.67 & 250.52 & 236.30 \\
\hline Kruskal-Wallis H & $\begin{array}{l}\mathrm{H}(3)=34.750 \\
\mathrm{p}<0.001\end{array}$ & $\begin{array}{l}H(3)=47.549 \\
p<0.001\end{array}$ & $\begin{array}{l}\mathrm{H}(3)=34.873 \\
\mathrm{p}<0.001\end{array}$ & $\begin{array}{l}\mathrm{H}(3)=35.317 \\
\mathrm{p}<0.001\end{array}$ & $\begin{array}{l}H(3)=15.407 \\
p=0.001\end{array}$ \\
\hline
\end{tabular}

Table 7. Spearman's correlation coefficients $\left(R_{S}\right)$ between age (stratified by gender) and the four domains and the GHF.

\begin{tabular}{|c|c|c|c|c|c|}
\hline$\overline{\text { Variables and Statistica }}$ & Domain & & & & GHF \\
\hline Tests & Physica & hPsycholo & Social r & sEnvironment & \\
\hline Age by Gender (Rs): & & & & & \\
\hline Male & $-.304 * \mathrm{~b})$ & $-.239 * \mathrm{a})$ & $-.207 * \mathrm{a})$ & $-.287 * \mathrm{~b})$ & $-.176^{* * a}$ \\
\hline Female & $-.211 * a)$ & $-.165 * * a)$ & $-.197 * a)$ & $-.245 * \mathrm{a})$ & $-.100^{a)}$ \\
\hline$* p<0.01$ (highly signific & cant) & & & & \\
\hline$* * p<0.05$ (significant) & & & & & \\
\hline a) Weak ( ) see (80) & & & & & \\
\hline b) Moderate ( ) see (80 & & & & & \\
\hline
\end{tabular}


Table 8. Biological and sociodemographic factors that comprise the Portuguese WHOQOL-BREF that were identified as possible predictors of the QOL domains; only those considered statistically significant in linear regression models using blocks (BLRM) are shown.

Domains

Standardized coefficients $B L R M-R^{2}$

\begin{tabular}{|c|c|c|c|}
\hline & & & $(p)$ \\
\hline \multirow[t]{5}{*}{ Physical Health } & Block 1/Age & $-0.156^{*}$ & \multirow[t]{2}{*}{0.157} \\
\hline & Gender & 0.197* & \\
\hline & \multirow{3}{*}{\begin{tabular}{|l|l} 
Block 2 & Knows how to read and/or write \\
& $1^{\text {st_- }}{ }^{\text {th }}$ grade \\
More education
\end{tabular}} & $0.133^{* *}$ & \multirow[t]{3}{*}{$p<0.001$} \\
\hline & & $0.219^{*}$ & \\
\hline & & $0.229 *$ & \\
\hline \multirow[t]{4}{*}{ Psychological } & Block 1 Gender & $0.112^{* * *}$ & \multirow[t]{2}{*}{0.171} \\
\hline & \multirow{3}{*}{\begin{tabular}{|l|l|} 
Block 2 & $1^{\text {st }} 4^{\text {th }}$ grade \\
& More education \\
& Married/Living as Married
\end{tabular}} & $0.265 *$ & \\
\hline & & $0.278^{*}$ & \multirow[t]{2}{*}{$p<0.001$} \\
\hline & & $0.153^{*}$ & \\
\hline \multirow{4}{*}{ Social Relationships } & Block 1- & & \multirow{4}{*}{$\begin{array}{l}0.104 \\
p<0.001\end{array}$} \\
\hline & \multirow{3}{*}{\begin{tabular}{|l|l|} 
Block 2 & $1^{\text {st }} 4^{\text {th }}$ grade \\
& More education \\
& Married/Living as Married
\end{tabular}} & $0.214 *$ & \\
\hline & & $0.250^{*}$ & \\
\hline & & $0.114 * *$ & \\
\hline \multirow[t]{4}{*}{ Environment } & Block 1/Age & $-0.161 *$ & \multirow{4}{*}{$p<0.001$} \\
\hline & Block 2 Knows how to read and/or write & $0.127 * *$ & \\
\hline & $1^{\text {st }}-4^{\text {th }}$ grade & $0.256^{*}$ & \\
\hline & More education & $0.229 *$ & \\
\hline
\end{tabular}

$* p<0.01$ (highly significant)

$* * p<0.05$ (significant)

\section{Graph 1}

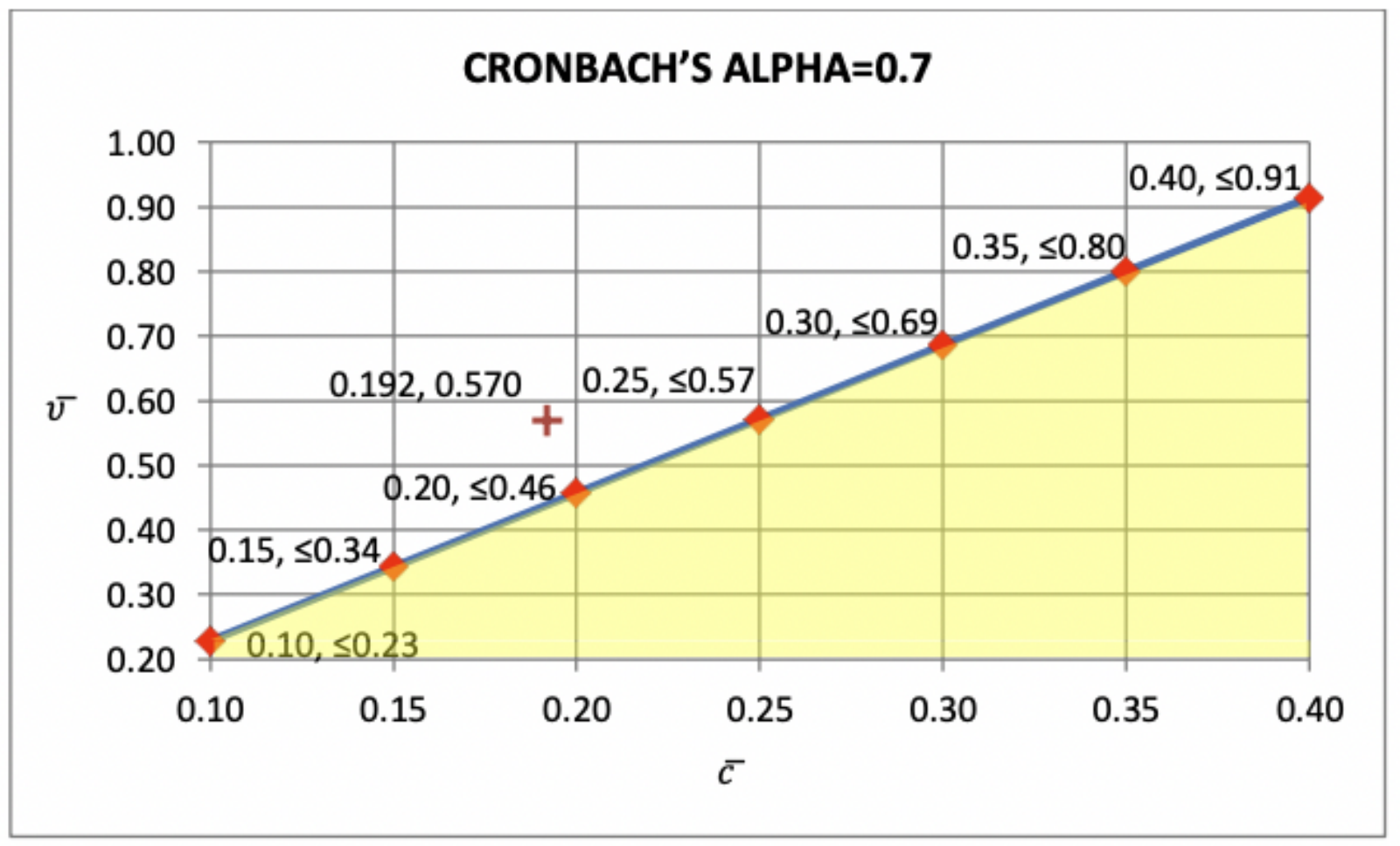


Figures
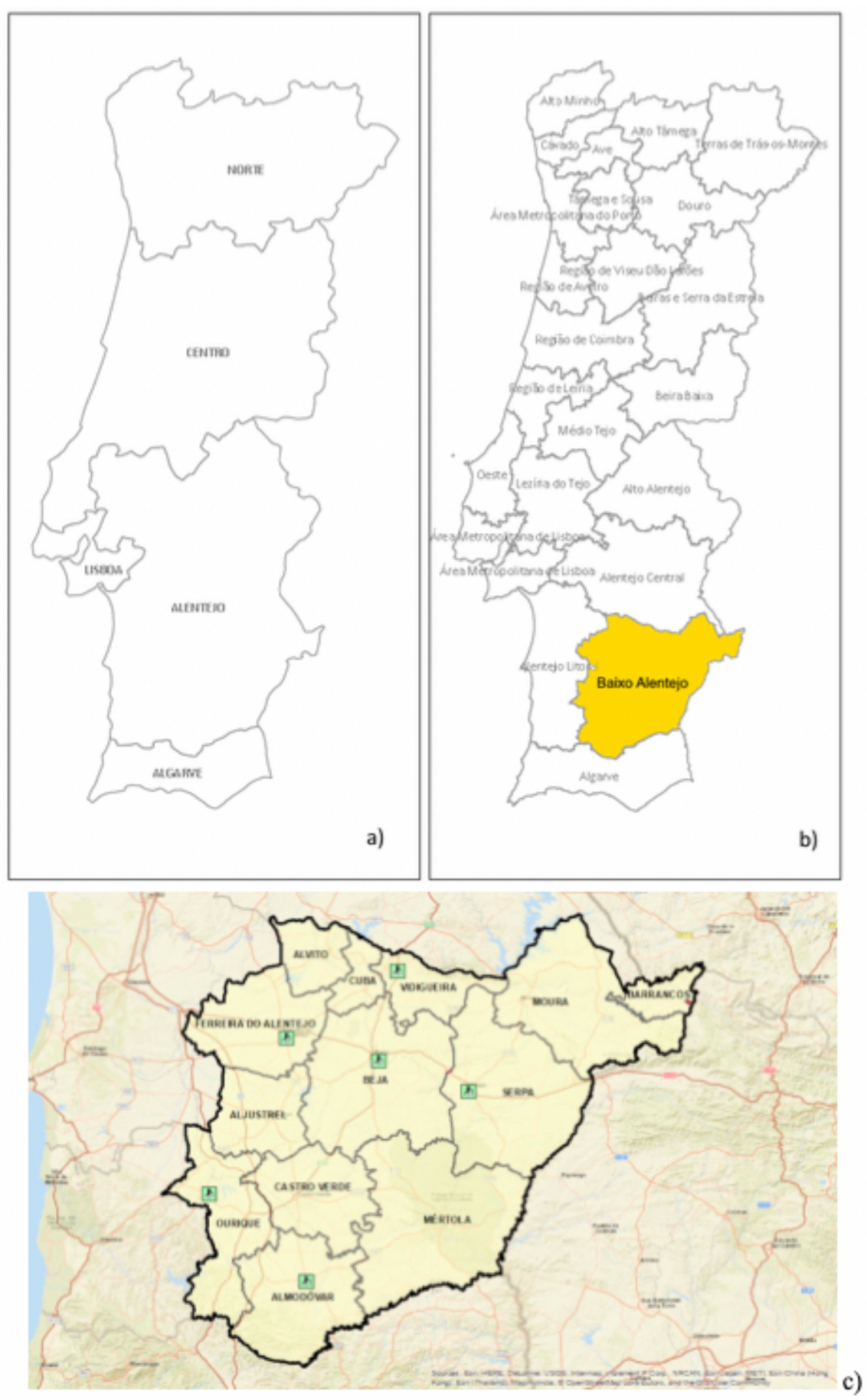

Figure 1

a) Portugal main territory divided into five Regional Health Administrations; b) Sub-regions of the five Regional Health Administrations; c) RBA, which presents the same geographical boundaries of ULSBA is composed of 13 Municipalities (delimited by the gray lines) and only six ECCls teams shown by the green symbols. 


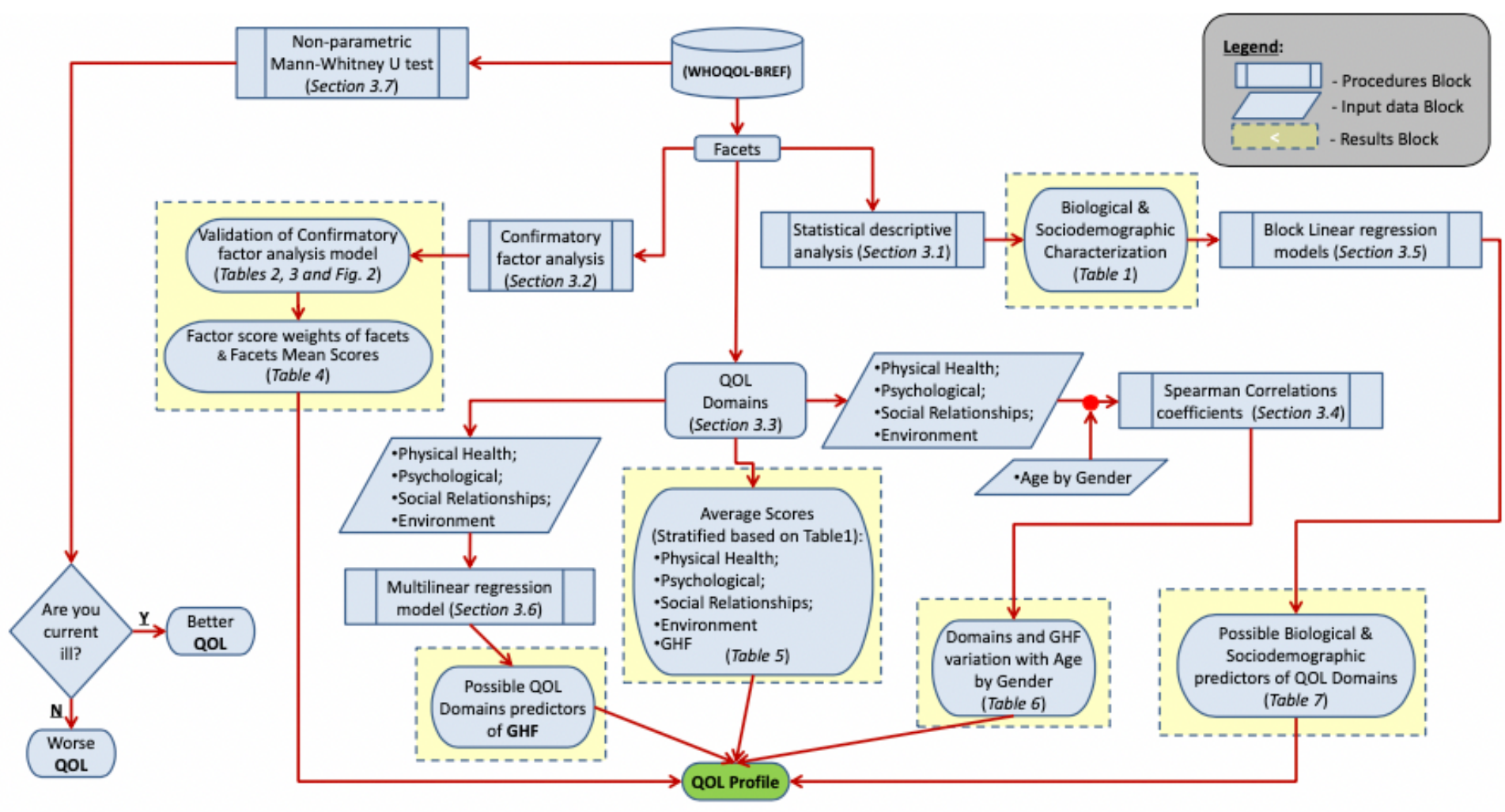

Figure 2

Flow diagram of analyses to understand the proposed QOL profile. 


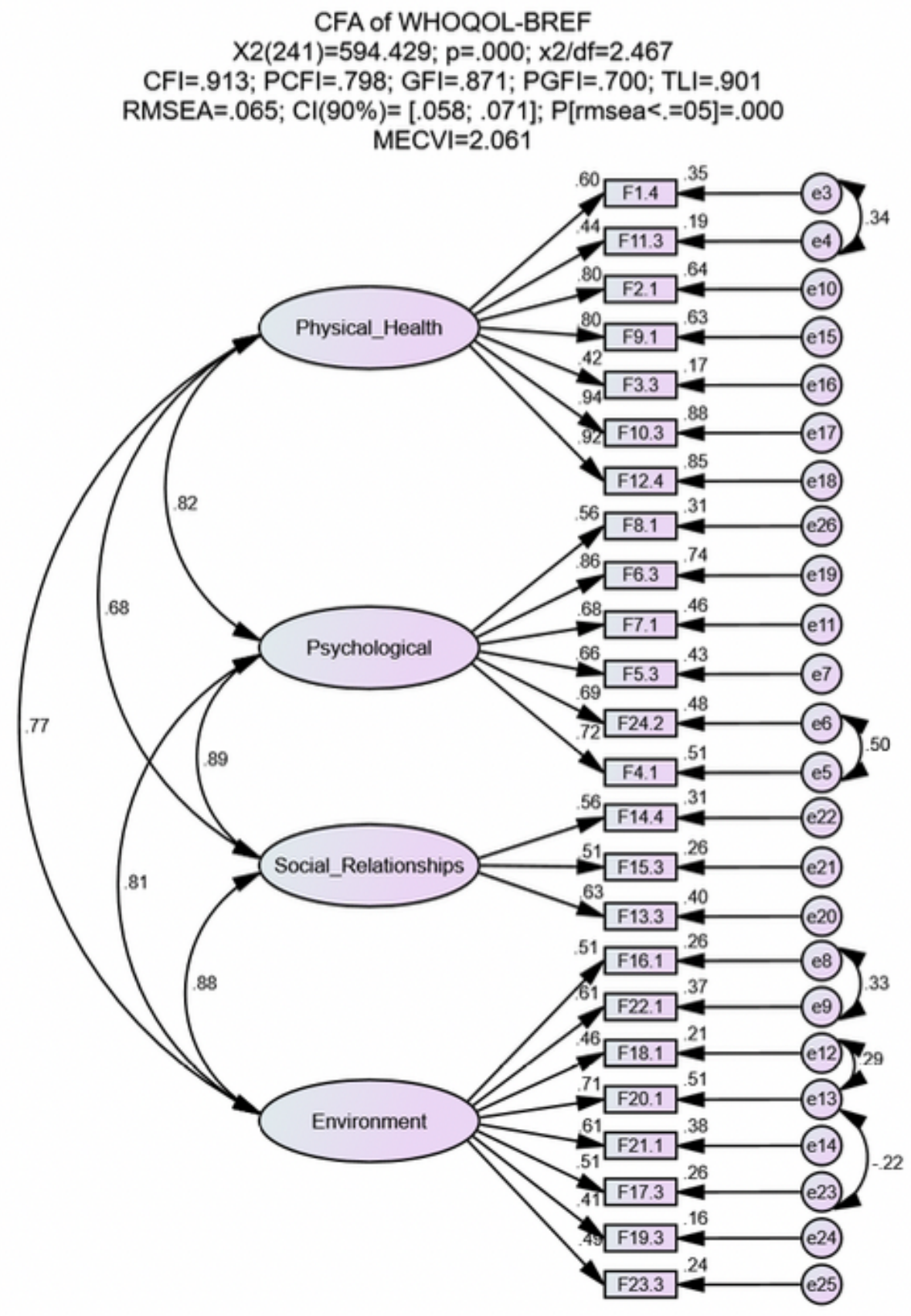

Figure 3

Fitted factorial model of the Portuguese WHOQOL-BREF, after correlating the measurement errors of facets whose Ml suggested their correlation (adopted Ml>11). The SRMR index is equal to 0.0599 . 


\section{Coast land dimensions}

-Greater resident working population

-More school opportunities

-More literate citizens

-Less unemployment

-Major cities

- Higher number of enterprises

- Better job opportunities

- Higher population density

- Greater resident population

-More opportunities for acquiring new information and skills

-Fewer suicides

-Less lowliness

-Good access to new technologies

-More access to public transportation network

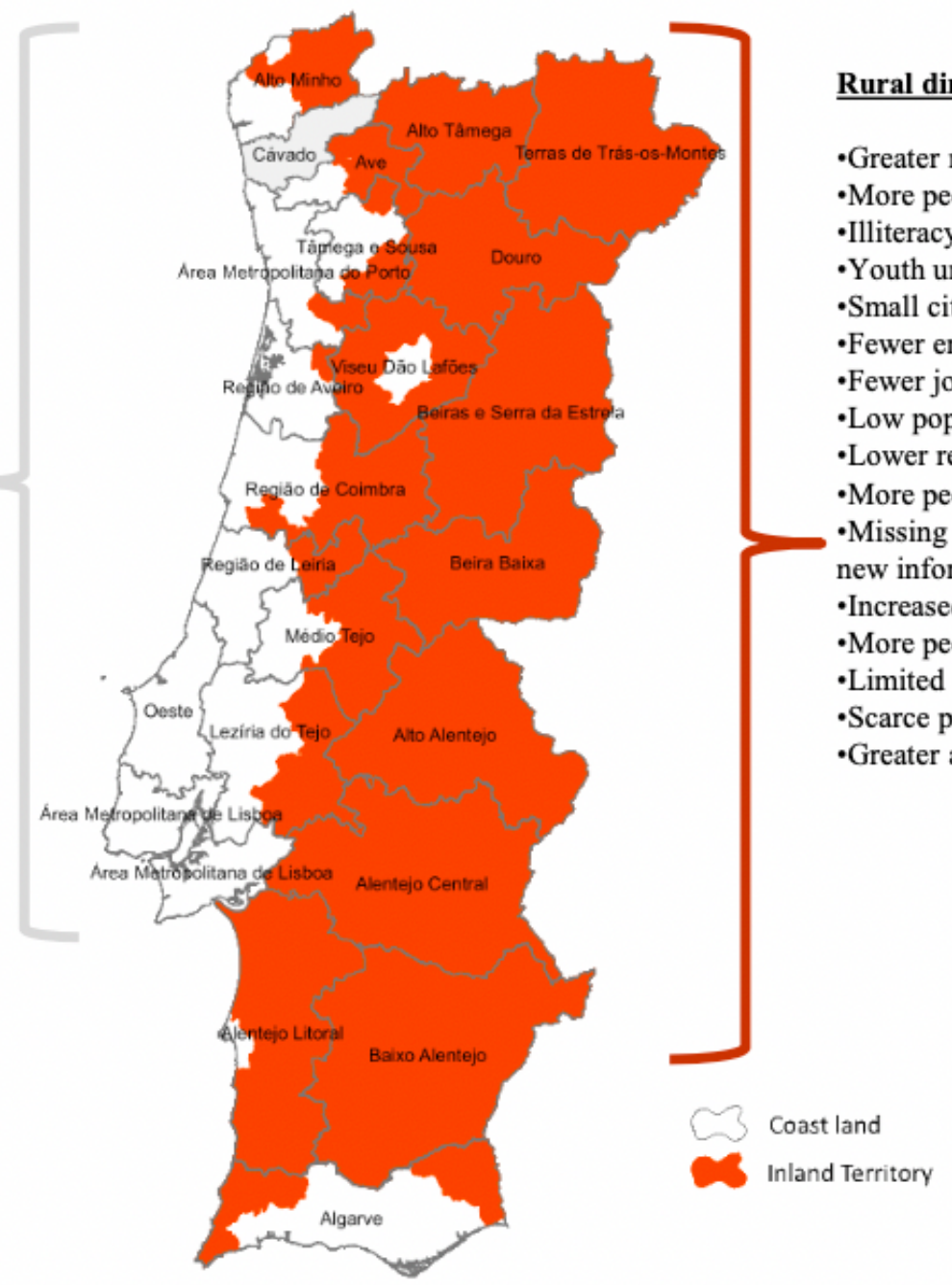

\section{Figure 4}

Portugal main territory, divided according to the National land classification: (i) inland area; (ii) coast land (adapted from (79)). This figure summarizes the characteristics of the territory under various dimensions, from the inland territory and coast land perspectives. 